\title{
Effect of Graphene Addition on Anticorrosion Performance of Two Kinds of Epoxy Coatings
}

Shuai Wang ${ }^{l}$, Rui Ding ${ }^{1}$, Xiaodong Zhao ${ }^{l,}$, Qiang $F u^{l}$, Hao Sun ${ }^{l}$, Shuyue Chen ${ }^{l}$, Zhongyi An ${ }^{l}$, Yan $\mathrm{Li}^{2}$, Xinlei $Q u^{3}$

${ }^{1}$ School of Ocean, Yantai University, Yantai 264005, China;

${ }^{2}$ Qingdao Branch of Naval Aeronautical Engineering Academy, Qingdao 266041, China;

${ }^{3}$ Shandong Nanshan Aluminum Co., Ltd., Yantai 265706, China

*E-mail: danielxdzhao@aliyun.com

doi: $10.20964 / 2020.03 .96$

Received: 22 October 2019 / Accepted: 9 January 2020 / Published: 10 June 2020

Graphene is a kind of two-dimensional lamellar nano-material with excellent barrier property, and it has important application in the field of anticorrosive coatings. The effect of graphene addition on the corrosion resistance of zinc-rich epoxy coating and glass flake epoxy coating was investigated by opencircuit potential( $\left.E_{o c p}\right)$, AC impedance and corrosion morphology. The results showed that the radius of arc resistance of epoxy zinc-rich coating with graphene was smaller than that of epoxy zincrich coating without graphene. The arc resistance with epoxy glass flake coating decreased gradually in 528h. It showed from the corrosion morphology observation that the addition of graphene improved the corrosion resistance of the zinc-rich coating, but reduced the corrosion resistance of the epoxy glass flake coating.

Keywords: Graphene; Epoxy zinc-rich coating; Epoxy glass flake coating; Electrochemical analysis

\section{$\underline{\text { FULL TEXT }}$}

(C) 2020 The Authors. Published by ESG (www.electrochemsci.org). This article is an open access article distributed under the terms and conditions of the Creative Commons Attribution license (http://creativecommons.org/licenses/by/4.0/). 